\title{
Phosphatases of $\alpha$-synuclein, LRRK2, and tau: important players in the phosphorylation-dependent pathology of Parkinsonism
}

\author{
Jean-Marc Taymans* and Veerle Baekelandt \\ Department of Neurosciences, Laboratory for Neurobiology and Gene Therapy, KU Leuven, Leuven, Belgium
}

\section{Edited by:}

Allegra Via, Sapienza University, Italy

Andreas Zanzoni, Inserm

Technological Advances for Genomics

and Clinics, UMR1090, France

\section{Reviewed by:}

Eric Yang, Johnson and Johnson, USA Christian Johannes Gloeckner,

Helmholtz Zentrum München,

Germany

\section{*Correspondence:}

Jean-Marc Taymans, Jean-Pierre

Aubert Research Center, UMR837,

Rue Polonovski - 1 Place de Verdun,

59045 Lille, France

e-mail: jean-marc.taymans@inserm.fr
An important challenge in the field of Parkinson's disease (PD) is to develop disease modifying therapies capable of stalling or even halting disease progression. Coupled to this challenge is the need to identify disease biomarkers, in order to identify pre-symptomatic hallmarks of disease and monitor disease progression. The answer to these challenges lies in the elucidation of the molecular causes underlying PD, for which important leads are disease genes identified in studies investigating the underlying genetic causes of PD. LRRK2 and $\alpha$-syn have been both linked to familial forms of PD as well as associated to sporadic PD. Another gene, microtubule associated protein tau (MAPT), has been genetically linked to a dominant form of frontotemporal dementia and parkinsonism linked to chromosome 17 (FTDP-17) and genome-wide association studies report a strong association between MAPT and sporadic PD. Interestingly, LRRK2, $\alpha$-syn, and tau are all phosphorylated proteins, and their phosphorylation patterns are linked to disease. In this review, we provide an overview of the evidence linking LRRK2, $\alpha$-syn, and tau phosphorylation to PD pathology and focus on studies which have identified phosphatases responsible for dephosphorylation of pathology-related phosphorylations. We also discuss how the LRRK2, $\alpha$-syn, and tau phosphatases may point to separate or cross-talking pathological pathways in PD. Finally, we will discuss how the study of phosphatases of dominant Parkinsonism proteins opens perspectives for targeting pathological phosphorylation events.

\footnotetext{
Keywords: PP1, PP2A, phosphorylation, phosphatase, Parkinson disease, LRRK2, alpha-synuclein, tauopathies, tau proteins
}

\section{INTRODUCTION}

Parkinson's disease (PD) is an incurable disease of aging characterized by the progressive death of dopaminergic cells in the midbrain as well as by $\alpha$-synuclein-rich intracytoplasmic depositions called Lewy bodies (LBs). Treatments which alleviate disease symptoms have been available for several decades; however, these do not halt disease progression. The development of disease-modifying therapies to replace the symptomatic treatments is therefore a major priority in the biomedical research field. Genetic studies of families with a history of PD (genetic linkage studies) as well as of PD patient groups compared to matched groups of healthy individuals (genetic association studies) have identified genes and genomic variants which contribute to the development of PD (Gasser, 2009; Nalls et al., 2011). These studies have revealed at least 20 PD genes, many of which are currently the subject of studies aiming to understand their biology and disease mechanisms. For instance, several PD genes, such as parkin, DJ-1, Pten induced kinase 1 (PINK1), or ATP13A2, contribute to early onset autosomal recessive forms of Parkinsonism. Other genes are linked to Parkinsonism in an autosomal dominant fashion and are responsible for early onset forms of PD ( $\alpha$-synuclein duplications or triplications, some families with mutated $\alpha$-synuclein) as well as the more common late onset forms of Parkinsonism ( $\alpha$-synuclein mutants, tau, LRRK2, VPS35, or EIF4G1; Houlden and Singleton, 2012). In this review, we focus on the dominant proteins $\alpha$-synuclein, tau, and LRRK2 in light of the importance of their phosphorylation for their biological functioning.

Mutations in $\alpha$-synuclein (SNCA, PARK1/4) and mutations in leucine-rich repeat kinase type 2 (LRRK2, PARK8) are linked to autosomal-dominant forms of PD (Gasser, 2009). Also, although protein deposition of microtubule associated protein tau (MAPT) is a feature of Alzheimer's disease (AD), MAPT gene mutations cause frontotemporal dementia (FTD) with Parkinsonism. Interestingly, these three dominant genes in Parkinsonism (MAPT, SNCA, and LRRK2) have also been identified as risk factors for sporadic PD in genome-wide association studies (GWAS; Taymans and Cookson, 2010; Sharma et al., 2012). The dominant mode of disease transmission through these genes also suggests a gain of toxic function mechanism pointing to an inhibition of toxic function as potential therapeutic strategies.

LRRK2, $\alpha$-syn, and tau are all phosphorylated proteins, and their phosphorylation patterns are linked to disease (Lobbestael et al., 2012; Tenreiro et al., 2014). Early work showed that hyperphosphorylation of tau is correlated to pathology of tauopathies and phosphorylation of $\alpha$-syn at serine 129 is correlated to synucleinopathies (for reviews, see references Martin et al., 2011; Tenreiro et al., 2014); therefore much work has focused on identifying and characterizing kinases of these proteins (for reviews, see references 
Vancraenenbroeck et al., 2011; Martin et al., 2013b; Tenreiro et al., 2014). The characterization of LRRK2 phosphorylation and the link to disease is still underway although some evidence suggests that a site-dependent mixed phosphorylation state is indicative of disease. Tau and synuclein kinases have been considered as potential therapeutic targets for synucleinopathies and tauopathies and several compounds have been developed for these kinases and tested in preclinical models (for reviews on these topics, see references Vancraenenbroeck et al., 2011; Kramer et al., 2012; Tell and Hilgeroth, 2013). In this review, we will discuss the second main component in the regulation of protein phosphorylation of LRRK2, $\alpha$-syn, and tau, namely phosphatases. We will briefly introduce the three proteins and discuss what is known about their dephosphorylation and which phosphatases and phosphatase regulators are involved. We will also discuss the relationships between the three proteins with regards to their cognate phosphatases and discuss targeting of phosphatase holoenzymes of LRRK2, $\alpha$-syn, and tau as a potential phosphomodulatory therapeutic approach.

\section{ALPHA-SYNUCLEIN}

The involvement of $\alpha$-syn in PD was initially identified through genetic linkage studies in a small number of families (Polymeropoulos etal., 1997), including mutations as well as gene duplications (Chartier-Harlin et al., 2004) and triplications (Singleton et al., 2003). Recently, strong association was shown between $\alpha$-syn and sporadic PD in GWAS (Satake et al., 2009; Simon-Sanchez et al., 2009). Also, $\alpha$-syn is a major component of LBs (Spillantini et al., 1997). These arguments illustrate that $\alpha$-syn is a central player in the pathogenesis of PD.

Studies investigating the phosphorylation of $\alpha$-syn in diseased and aged brains have shown that $\alpha$-syn can be phosphorylated at serines (S87, S129) as well as at several tyrosines including Y125, Y133, and Y136 (Figure 1). The pY125 modification has been reported to be inversely correlated with PD-related pathology. Indeed, pY125 appears to protect brains against $\alpha$-syn mediated toxicity, as this modification is reduced in aged human brain tissue and absent in brain tissue affected by Lewy body dementia (Chen and Feany, 2005; Chen etal., 2009). The pS129 modification on the other hand is most often correlated with PD pathology. This notion is primarily supported by the finding that the majority of $\alpha$-syn in LBs in postmortem PD brains is phosphorylated at S129 (pS129; Fujiwara et al., 2002; Hasegawa et al., 2002; Anderson et al., 2006). The S129 phosphorylation of $\alpha$-syn in aggregates has also been observed in animal models of PD (Kahle et al., 2000; Neumann et al., 2002; Takahashi et al., 2003). Mechanistic studies have shown that aggregated forms of $\alpha$-syn are more prone to phosphorylation and that pS129 phosphorylated aggregates accumulate as the disease progresses (Waxman and Giasson, 2008; Mbefo et al., 2010; Paleologou et al., 2010; Waxman and Giasson, 2011), suggesting that the degree of $\alpha$-syn pS129 phosphorylation is an indicator of disease progression.

The link between S129 phosphorylation and PD pathology has fueled an interest in modulating $\alpha$-syn phosphorylation at S129 as a potential therapy for PD (Vancraenenbroeck et al., 2011). Multiple kinases have been identified which phosphorylate $\alpha$ syn at S129, with most evidence pointing to polo-like kinase 2 (PLK2) as the primary phosphorylated of $\alpha$-syn S129 [for an extended up to date review of $\alpha$-syn phosphorylation, please refer to Tenreiro etal. (2014)]. A straightforward therapeutic approach based on reducing $\alpha$-syn phospho-S129 would be to inhibit PLK2 kinase activity; however some contradictory findings should be taken into account. For instance, overexpression of PLK2 in rat brain using adeno-associated viral vectors can suppress $\alpha$-syn toxicity by promoting autophagy-mediated degradation of phospho-S129 $\alpha$-syn (Oueslati et al., 2013). Therefore, therapies based on modulating $\alpha$-syn phospho-S129 appears to require an optimal phosphorylation level rather than a complete dephosphorylation.

\section{PHOSPHATASES OF $\alpha$-SYN}

Few studies have sought to identify phosphatases of $\alpha$-syn (Braithwaite et al., 2012); however, concurring data point to PP2A as a major phosphatase of the S129 site. For instance, PP2A enzyme but not PP1 is shown to dephosphorylate $\alpha$-syn-pS129 in vitro (Lee et al., 2011), and treatment of cells with the PP2A inhibitor okadaic acid (OA) but not the PP1 inhibitor tautomycin leads to an increased level of $\alpha$-syn-pS129. Further characterization showed that $\alpha$-syn-pS129 was increased upon knockdown of the PP2A catalytic subunit and when PP2A enzyme is methylated.

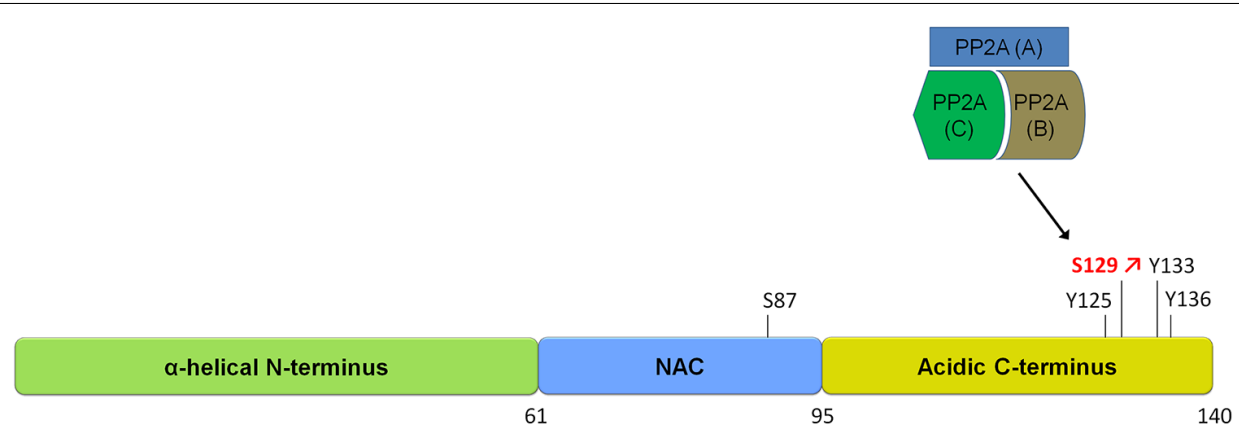

FIGURE 1 | Schematic of $\alpha$-synuclein and its phosphorylation sites. $\alpha$-syn is a small protein of 140 amino acids in length. It is subdivided into three domains, an N-terminal alpha-helical domain, a central NAC domain (standing for non-Abeta-component) and an acidic C-terminal domain. The S129 site is hyperphosphorylated in disease and is regulated by a phosphatase of the heterotrimeric PP2A class. Please refer to Table 1 for an overview of studies on phosphatases regulating $\alpha$-syn phosphorylation. 
It is important to note that the phosphatases of the PP2A class function in complexes called holoenzymes, which are composed of regulatory and catalytic phosphatase subunits. In the case of PP2A phosphatases, these are composed of a catalytic subunit (PPP2CA or PPP2CB) together with a scaffold subunit $(\mathrm{A} \alpha$ or $\mathrm{A} \beta$ ) and a regulatory subunit (of which there are four families, B, B', $B^{\prime \prime}$, and $\mathrm{B}^{\prime \prime \prime}$, each with 2-5 different members). The precise heterotrimeric composition of the holoenzyme guides PP2A to specific substrate sites. Accordingly, the testing of four different holoenzyme compositions shows that holoenzymes with regulatory subunits of the $\mathrm{B}$ family are more efficient at dephosphorylating $\alpha$-syn-pS129 than those of the $\mathrm{B}^{\prime}$ and $\mathrm{B}^{\prime \prime}$ families. Interestingly, $\alpha$-syn may function in a feedback loop with PP2A, with studies reporting that $\alpha$-syn has the ability to activate PP2A activity (Peng et al., 2005) and that phospho-S129 $\alpha$-syn is less efficient at activating PP2A (Lou et al., 2010).

PP2A enzymes have the particularity that their enzymatic activity is positively regulated by its methylation which is itself regulated via the opposing activities of a PP2A-specific methyltransferase and a PP2A-specific methylesterase (PME). Accordingly, treatment of mice with the PME inhibitor eicosanoyl-5-hydroxytryptamide (EHT) increases PP2A methylation as well as decreased $\alpha$-synpS129 levels in brain and a concurrent reduction in synuclein pathology (Lee et al., 2011). Related to this, the diabetes drug metformin was shown to reduce $\alpha$-syn phosphorylation at S129 through activation of PP2A and inhibition of mammalian target of rapamycin (mTOR; Perez-Revuelta et al., 2014). These studies confirm a primordial role of PP2A in the phosphoregulation of $\alpha$-syn at S129 and also provide a proof-of-principle that phosphorylation levels of $\alpha$-syn can be modulated by targeting its phosphatases. Thus far, no phosphatases have been described for the tyrosine phosphorylation sites of $\alpha$-syn. An overview of $\alpha$-syn phosphatases is given in Table $\mathbf{1}$.

\section{LRRK2}

LRRK2 is a complex protein of 2527 amino acids containing several predicted functional domains (Figure 2). Several arguments underline the importance of LRRK2 for PD. First, LRRK2 is one of the most prevalent causes of monogenic PD. Furthermore, LRRK2 mutations are present in apparently sporadic cases of PD, with prevalences of $2 \%$ to up to $40 \%$ in certain population groups and LRRK2 was recently genetically associated to PD in several independent GWAS (Satake et al., 2009; Simon-Sanchez et al., 2009). Finally, PD patients carrying the LRRK2 mutations show a clinical and neuropathological profile which is virtually indistinguishable to sporadic PD (Healy et al., 2008), indicating that LRRK2 may contribute to a PD disease pathway common to both familial and sporadic $\mathrm{PD}$.

LRRK2 is a highly phosphorylated protein and phosphosite mapping studies have distinguished two notable clusters of phosphorylation sites, one in or near the Ras of complex proteins (ROC) domain (Greggio et al., 2009; Kamikawaji et al., 2009) and another in the interdomain region between the ankyrin repeat (ANK) and leucine rich repeat (LRR) domains (see Figure 2; West et al., 2007; Gloeckner et al., 2010; Nichols et al., 2010; see reference Lobbestael et al., 2012 for a detailed overview of studies reporting LRRK2 phosphorylation sites).

The physiological and pathological relevance of LRRK2 phosphorylation has only just begun to be described. For instance, phosphosites of the ANK-LRR interdomain region, including the S910/S935/S955/S973 sites, are sites phosphorylated by upstream kinases. These sites are detectable in basal conditions in multiple cellular and tissular systems, including for endogenous LRRK2 in Swiss 3T3 or NIH3T3 cells (Nichols etal., 2010; Lobbestael et al., 2013), mouse primary neurons (Lobbestael et al., 2013), mouse brain, kidney, and lung (Deng etal., 2011; Choi etal., 2012; Zhang et al., 2012; Delbroek et al., 2013), mouse embryonic fibroblasts (Dzamko et al., 2012), mouse bone marrow derived macrophages (Dzamko et al., 2012) and human peripheral blood mononuclear cells (Dzamko et al., 2013). The S910 and S935 sites mediate an interaction of LRRK2 with 14-3-3 proteins and regulate LRRK2 cellular localization (Nichols et al., 2010). The search for the kinases responsible for phosphorylating LRRK2 at this cluster is still ongoing. Studies in vitro and in COS-7 cells have suggested a role for protein kinase A as an upstream kinase of the S910-S935 sites (Muda et al., 2014), however, these findings are not confirmed in other cell types such as HEK293T cells (Reynolds et al., 2014), suggesting cell-specific mechanisms of phosphorylation. This is

Table 1 | Overview of studies reporting phosphatases regulating $\alpha$-syn phosphorylation.

Site Identified phosphatase Comments, references

S129 PP2A

In vitro incubation with PP2A [catalytic subunit $\mathrm{C} \alpha$ (PPP2CA), regulatory subunit $\mathrm{B} \alpha$ (PPP2R2A)] dephosphorylates $\alpha$-syn S129 better than with B' $\alpha$ (PPP2R5A), B' $\gamma$ (PPP2R5C), or B' (PPP2R3A). Knockdown of PPP2CA or PPP2R2A increases $\alpha$-syn $\mathrm{S} 129$ phosphorylation (Lee et al., 2011).

PPP2R1A siRNA mediated knockdown of PPP2R1A (Protein phosphatase 2 (formerly 2A), regulatory subunit A, alpha isoform) reported to decrease $\alpha$-syn S129 phosphorylation levels in neuroblastoma derived cells (Henderson-Smith etal., 2013).

PTPRA siRNA mediated knockdown of PPP3R1 (Protein tyrosine phosphatase, receptor type, A) reported to decrease $\alpha$-syn S129 phosphorylation levels in neuroblastoma derived cells (Henderson-Smith etal., 2013).

PPP3R1 siRNA mediated knockdown of PPP3R1 (Protein phosphatase 3 (formerly 2B), regulatory subunit B, alpha isoform) found to increase $\alpha$-syn S129 phosphorylation levels in neuroblastoma derived cells (Henderson-Smith et al., 2013).

See text for references to reviews discussing a-syn kinases. 


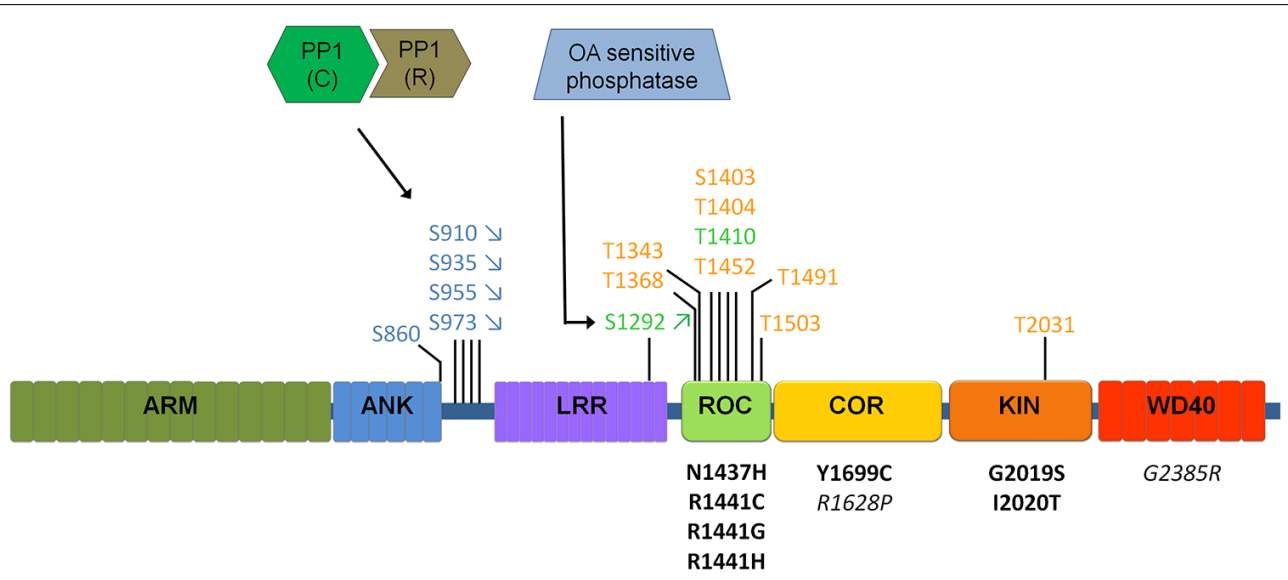

FIGURE 2 | Schematic of LRRK2 domain structure and currently identified LRRK2 phosphatases. Phosphorylation sites are indicated above the LRRK2 schematic, for those sites confirmed independently by at least two different groups. Sites represented in blue indicate cellular transphosphorylation sites, in orange in vitro autophosphorylation sites and in green autophosphorylation sites confirmed in cells. Disease mutants are indicated below the schematic in black, mutations in italics are risk factor mutations. Arrows (for S910/S935/S955/S973/S1292) indicate the most common regulation of phosphorylation (up or down) observed across most disease mutants. Different sites are likely regulated in different ways, including through PP1 and a yet to be defined phosphatase sensitive to okadaic acid (OA). Please refer to Table 2 comparing the regulation of phosphorylation at $\$ 935$ compared to $\mathrm{S} 1292$. further supported by the work of Dzamko et al. (2012) who show that inhibitor of kappa B kinases (IKKs) phosphorylate LRRK2 in bone marrow-derived macrophages upon activation of tolllike receptor signaling which is specific to immune cells. The phosphorylation pattern of LRRK2 is completely different from that of its closest homolog LRRK1 which does not contribute to $\mathrm{PD}$, suggesting that phosphorylation regulation of LRRK2 is a potential mechanism distinguishing LRRK2 from LRRK1 functionally.

Phosphorylation levels of the ANK-LRRK interdomain phosphosites are reduced for several pathogenic mutants such as R1441C/G, Y1699C, I2020T (Nichols et al., 2010; Li et al., 2011; Lobbestael et al., 2013). This observation suggests that the reduction in LRRK2 phosphorylation levels may be involved in the pathogenic mechanism of LRRK2 PD. A corollary of that conclusion is that reduced LRRK2 phosphorylation may be used as a biomarker, however, there are some caveats. For instance, the most prevalent LRRK2 variant in patients, G2019S, does not display reduced phosphorylation levels and a recent study reported no differences in LRRK2 S935 phosphorylation in PBMCs of PD patients compared to matched healthy individuals (Dzamko et al., 2013). Nevertheless, the striking phosphorylation reduction at the ANK-LRR sites seen in all other confirmed LRRK2 pathogenic mutants warrants further evaluation as a disease or diagnostic biomarker.

The other major group of phosphorylation sites for LRRK2 is comprised of autophosphorylation sites. These are sites which were initially identified on LRRK2 protein after in vitro incubation with ATP to allow the protein to autophosphorylate itself (Greggio etal., 2009; Kamikawaji et al., 2009; Gloeckner etal., 2010). The majority of these sites cluster in the ROC domain and studies with phospho-mimicking mutants show that at least some of these modifications (T1491D, T1503D) alter LRRK2 GTPbinding properties (Kamikawaji et al., 2009; Webber et al., 2011).
The precise physiological relevance of autophosphorylation sites is unknown since the majority of these sites are undetectable in cells, even on overexpressed protein. The notable exceptions are the T1410 site located in the ROC domain identified in overexpressed LRRK2 in HEK293T cells (Pungaliya et al., 2010), the S1058 (Reyniers et al., 2014), and the S1292 site (Gloeckner et al., 2010; Pungaliya et al., 2010; Sheng et al., 2012), located in the 3rd and 13th of the 14 leucine-rich repeats of the leucinerich repeat domain, respectively, just outside the ROC domain (Vancraenenbroeck et al., 2012). These reports suggest that at least some autophosphorylation events are occurring in cells. Specifically, the S1292 site has been characterized in more detail and displays a number of interesting features. The S1292 site is one of the few autophosphorylation sites located outside ROC. The site is phosphorylated at detectable levels in basal conditions in LRRK2 overexpressed in cell lines or in transgenic mice (Sheng et al., 2012) as well as on endogenous LRRK2 in lymphocytes (Reynolds et al., 2014). In contrast to what is described for the ANK-LRR interdomain sites, the S1292 levels are increased in cells for the majority of pathogenic mutants and decreased in LRRK2 kinase-dead variants (Sheng et al., 2012; Reynolds et al., 2014). Increased phosphorylation levels at S1292 may therefore be indicative of LRRK2's pathogenic state; however, this remains to be tested in $\mathrm{PD}$ patients. Because the kinase activating mutant G2019S shows increased phospho-S1292 and kinase dead mutants show reduced phospho-S1292, it may be suggested that phospho-S1292 levels are indicative of LRRK2 kinase activity in cells, however, some discrepancies appear. For instance, other mutants, such as N1437H, R1441C, or R1441G which are significantly less active in their kinase activity than G2019S nevertheless display similar phospho-S1292 levels relative to the G2019S (Sheng et al., 2012; Reynolds et al., 2014). Two other pathogenic mutants, Y1699C and I2020T, which display kinase activity similar to WT or slightly increased, show varying phospho-S1292 
levels depending on the system tested. Indeed, the Y1699C mutant displays increased phospho-S1292 levels in stable overexpression HEK293T cells (Reynolds et al., 2014) and unchanged phosphoS1292 levels in transfected HEK293T cells (Sheng et al., 2012), while the inverse is true for the I2020T mutant. Further work will be required to elucidate the precise regulation of phosphoS1292 levels in LRRK2. It also remains to be shown whether the conclusions here for S1292 (an autophosphorylation site which occurs in cells) also hold true for other autophosphorylation sites or whether this is a new 'class' of sites (besides the ROC autophosphorylation cluster and the ANK-LRR interdomain cluster).

Of importance for the development of LRRK2 kinase inhibitors is that the majority of these sites is downregulated by kinase inhibitors and may therefore be used to assess inhibitor activity. For instance, the phosphorylation of autophosphorylation sites such as S1491 is inhibited by LRRK2 kinase inhibitors in vitro (Doggett et al., 2012). Also, cellular treatment with kinase inhibitors leads to a dephosphorylation of the ANK-LRR interdomain sites S910/S935/S955/S973 (Dzamko et al., 2010; Deng et al., 2011; Doggett et al., 2012) as well as the S1292 autophosphorylation site (Sheng et al., 2012; Reynolds et al., 2014). Intriguingly, although the ANK-LRR interdomain phosphorylations are not autophosphorylation sites, the observed dephosphorylation of LRRK2 by kinase inhibitors can be attributed to the activity of the inhibitors on LRRK2 itself.

In sum, the emerging picture of LRRK2 phosphorylation is that LRRK2 is a highly phosphorylated protein where at least two, perhaps three, classes of phosphorylation sites can be discerned (see Figure 2). A first class of phosphosites in LRRK2 is the in vitro autophosphorylation site class. These sites appear after in vitro autophosphorylation by purified LRRK2; however, their presence in cells is not confirmed. While these sites offer opportunities to develop assays of LRRK2 kinase activity, their physiological relevance is unclear. Further work will be required to determine whether these sites occur in physiological systems under specific conditions of activation, or whether the appearance of these phosphorylations is an in vitro phenomenon. A second class of LRRK2 phosphorylation sites may be termed 'cellular' phosphorylation sites, including those sites of the ANK-LRR interdomain region introduced above, exemplified by the S935 site. Finally, the third and most recent class of LRRK2 phosphorylation sites is the class of cellular autophosphorylation sites, exemplified by the S1292 site, which are detected in cells and which also increase after in vitro autophosphorylation. The cellular sites (S935) and cellular autophosphorylation sites (S1292) are the most physiologically relevant and the comparison of both sites (summarized in Table 2) suggests that these may be useful indicators of LRRK2 activity or pathology. With a few exceptions, pathogenic mutants of LRRK2 display decreased phospho-S935 levels and increased phospho-S1292 levels. It remains to be confirmed whether these changes can be used as diagnostic or disease biomarkers, either individually or together. Interestingly, cellular treatment with kinase inhibitors leads to a reduction of both S935 and S1292. Therefore, both sites are also useful as pharmacodynamic marker to assess activity of kinase inhibitors in cellular and animal models.

\section{Table 2 | Comparison of the two different LRRK2 phosphorylation sites pS935 and pS1292.}

\begin{tabular}{|c|c|c|}
\hline Parameter & pS935 & pS1292 \\
\hline Present in cells & YES & YES \\
\hline $\begin{array}{l}\text { Change after in vitro } \\
\text { autophosphorylation }\end{array}$ & NO CHANGE & INCREASE \\
\hline $\begin{array}{l}\text { Change after cellular } \\
\text { kinase inhibition }\end{array}$ & DECREASE & DECREASE \\
\hline N1437H vs. WT & I & HIGHER \\
\hline R1441C/G vs. WT & LOWER & HIGHER \\
\hline Y1699C vs. WT & LOWER & SIMILAR \\
\hline G2019S vs. WT & NO CHANGE & HIGHER \\
\hline I2020T vs. WT & LOWER & HIGHER \\
\hline G2385R vs. WT & LOWER & LOWER \\
\hline Regulation & IKK, PP1, +tbd & AutoP, +tbd \\
\hline Physiological role & $\begin{array}{l}\text { 14-3-3 binding, } \\
\text { subcellular localization }\end{array}$ & $\begin{array}{l}\text { Putative role in neurite } \\
\text { length regulation }\end{array}$ \\
\hline
\end{tabular}

Indicated is the regulation of phosphorylation levels at these sites by autophosphorylation, cellular kinase inhibition, or disease mutants. AutoP, autophosphorylation; tbd, to be discovered.

\section{PHOSPHATASES OF LRRK2}

We recently reported that protein phosphatase 1 (PP1) is a main phosphatase of the LRRK2 ANK-LRR interdomain sites (Lobbestael et al., 2013). The study first shows that of a panel of recombinant serine/threonine phosphatases, only protein phosphatase 1 can efficiently dephosphorylate LRRK2 in vitro. In vitro dephosphorylation was demonstrated on purified LRRK2 protein which was previously metabolically labeled by radioactive phosphates, showing that PP1 is responsible for dephosphorylation at the majority of LRRK2's phosphosites, a finding confirmed for 4 sites with phospho-specific antibodies, i.e., S910, S935, S955, and S973. Upon pharmacological inhibition of cells with either PP1 or PP2A phosphatase inhibitors, it was observed that PP1 but not PP2A inhibition could reverse LRRK2 dephosphorylation.

Interestingly, the effects of PP1 in LRRK2 phosphorylation could be confirmed in multiple cell types including HEK293T, SH-SY5Y neuroblastoma cells, mouse primary cortical neurons, U2OS osteosarcoma cells, NIH3T3 mouse fibroblast cells and A549 human lung cancer cells. This shows that PP1 is active as a LRRK2 phosphatase independent of the cell type tested, and it may be predicted that PP1 can dephosphorylate LRRK2 throughout the body.

Similar to PP2A phosphatases, PP1 class phosphatases are holoenzymes which are composed of one catalytic subunit, responsible for catalyzing the actual dephosphorylation event, and one regulatory subunit, responsible for directing the holoenzyme to its specific substrates. There are more than 150 PP1 regulatory subunits reported, allowing several 100 possible holoenzyme compositions (Bollen et al., 2010). This mode of functioning is necessary given that only three PP1 catalytic subunits are expressed in mammalian cells (PP1 $\alpha, \mathrm{PP} 1 \beta$, and PP $1 \gamma$; HGNC codes 
PPP1CA, PPP1CB, and PPP1CC) which on their own are insufficiently diverse to account for the specificity in the huge volume of phosphatase activity mediated by PP1. Indeed, PP1 together with PP2A (which is represented by only two catalytic subunits, PPP2CA and PPP2CB, see below) account for more than $90 \%$ of the protein phosphatase activity in eukaryotes (Moorhead et al., 2007; Virshup and Shenolikar, 2009). This is in stark contrast to the diversity for instance of kinases, of which there are $\sim 400$ serine/threonine kinases (Manning et al., 2002). Therefore, a key issue is to identify the composition of the PP1 holoenzyme by identifying the LRRK2-specific PP1 regulatory subunit which associates with the PP1 catalytic subunit.

There is little data available on the phosphatases involved in the regulation of LRRK2 phosphosites outside of the ANK-LRR interdomain region, however, initial evidence suggests that other phosphatases are at play. Work done at the S1292 site shows that inhibitor induced dephosphorylation of LRRK2 at S1292 is insensitive to the phosphatase inhibitors calyculin A (mixed PP1 and PP2A inhibitor) and OA (selective PP2A inhibitor; Reynolds et al., 2014), in contrast to what is observed at the $\$ 935$ site where inhibitor induced dephosphorylation is inhibited by calyculin A (Lobbestael et al., 2013). However, the low basal S1292 phosphorylation levels of the R1441G mutant is upregulated by both calyculin A and OA treatment (Reynolds et al., 2014), while the S935 phosphorylation levels of the same mutant is only upregulated by calyculin A (Lobbestael et al., 2013). These findings suggest the hypothesis that PP2A, rather than PP1, is the phosphatase system regulating R1441G LRRK2 at S1292.

\section{TAU}

It may seem surprising to discuss Tau in relation to PD pathogenesis, as this protein has a relatively long history as a protein involved in neurodegenerative dementias; however, accumulating evidence puts this protein to the forefront in $\mathrm{PD}$ with a number of reports pointing to specific properties of Tau in PD distinguishing it from Tau in other neurodegenerative disorders. Tau is a microtubule associating protein which is involved in several neurodegenerative diseases including $\mathrm{AD}$, progressive supranuclear palsy (PSP), corticobasal degeneration (CBD), and some cases of frontotemporal lobar dementia (FTLD). Although tau is mostly associated to dementias, the tau gene has also been identified as a risk factor for PD via genome wide association studies (GWAS; Sharma et al., 2012). The genetic association of MAPT locus variants with PD is a striking finding, and is in stark contrast with the fact that no genetic associations of the MAPT locus are observed in AD (Lambert et al., 2013), showing that tau contributes to both AD and PD but via separate mechanisms.

Tau can occur in six different splice isoforms ranging in size from 352 to 441 amino acids and at least 45 potential tau phosphorylation sites have been reported, including serine, threonine and tyrosine phosphorylation sites [see figure schematic representation of tau protein and the localization of phosphorylation sites, Figure 3; for reviews of tau phosphorylation, please refer to Martin et al. (2013a,b) and Tenreiro et al. (2014)]. Several kinases have been reported to phosphorylate tau. These include proline directed kinases [glycogen synthase kinase 3 (GSK3), cyclin dependent kinase 5 (CDK5), and $5^{\prime}$ adenosine monophosphateactivated protein kinase $(\mathrm{AMPK})]$, non-proline directed kinases [casein kinase 1 (CK1), microtubule affinity regulating kinases (MARKs), death associated protein kinase 1 (DAPK1), cyclic AMP-dependent protein kinase A (PKA) and dual specificity tyrosine-phosphorylation regulated kinase 1A (DYRK-1A)] as well tyrosine kinases including Fyn, Abl, and Syk. The inhibition of tau phosphorylation has been proposed as a therapeutic strategy in tauopathies including early phase clinical testing of GSK-3 $\beta$ inhibition (Del Ser et al., 2013).

Tau phosphorylation is important for tau function/dysfunction as hyperphosphorylation of tau is generally correlated with the formation of tau protein aggregates which are major components of neurofibrillary tangles, one of the main neuropathological hallmarks of $\mathrm{AD}$ which is also observed in other tauopathies including PD. Phosphorylated tau also more specifically influences

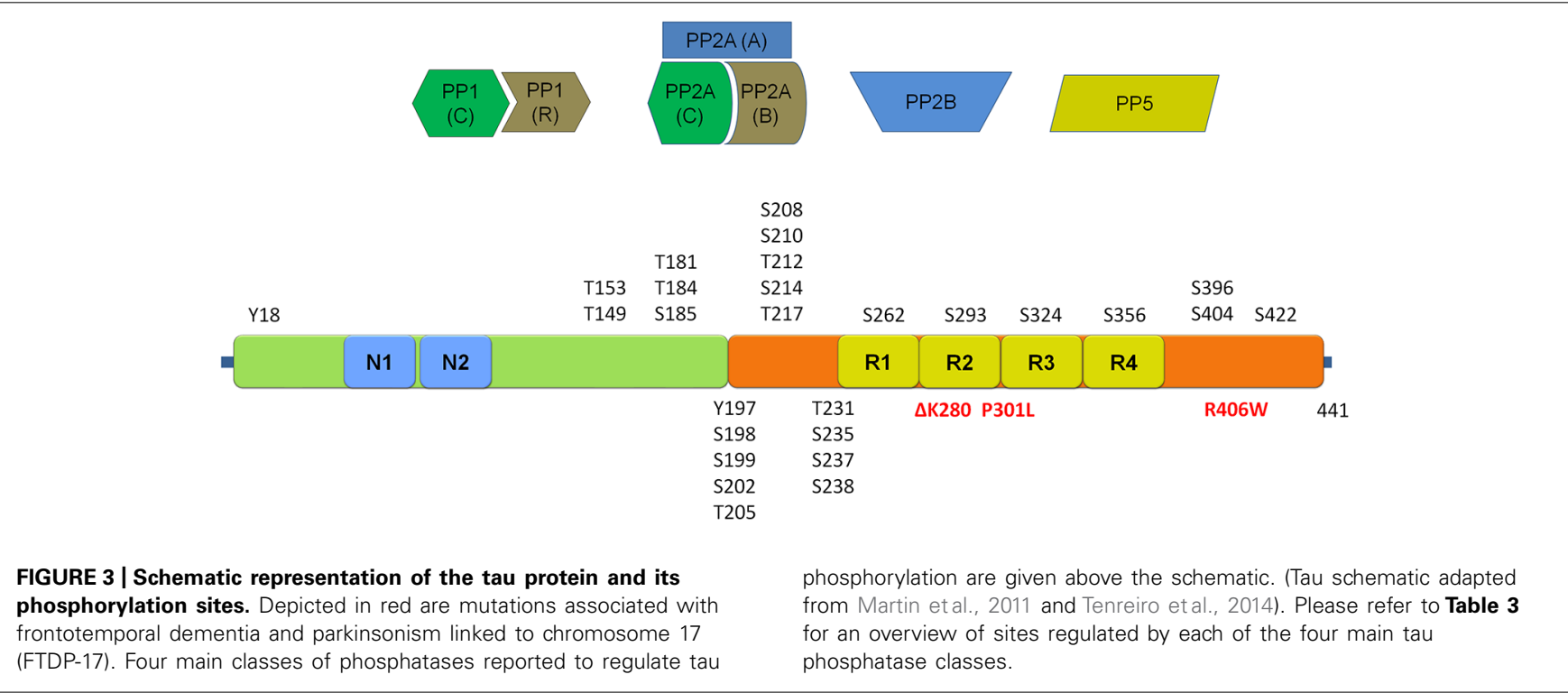


its affinity for microtubules and high phosphorylation levels of tau have been reported to negatively influence cytoskeleton, synaptic functions as well as cell viability (Buee et al., 2000). Recently, some work has appeared showing some differences in the tau phosphorylation pattern in post-mortem brain of tauopathies, including PD (Duka etal., 2013). This work revealed notable differences in phosphorylation patterns between PD and other tauopathies. For instance, S202, T205, S262, S409 are hyperphosphorylated in AD and DLB, but are unchanged in PD, while others such as T181, S184, S195, S198, S237, S400 are hyperphosphorylated in all three, $\mathrm{AD}, \mathrm{DLB}$, and $\mathrm{PD}$. It remains to be confirmed that these varying phosphorylation patterns are indeed related to the varying pathology observed in these different diseases.

\section{PHOSPHATASES OF TAU}

In light of the importance of tau phosphorylation for its pathology, several studies have sought to identify phosphatases dephosphorylating tau (reviewed in Martin et al., 2013a). These studies reveal a predominant role for PP2A, which is the most efficient phosphatase to dephosphorylate tau in vitro at S202, S262, and S356, but not S396 (Bennecib et al., 2000; Kuszczyk et al., 2009; Martin et al., 2009). This finding has been related to AD where to PP2A activity is reduced by up to $50 \%$ in $\mathrm{AD}$ brains (Voronkov et al., 2011; Martin et al., 2013a), observations pointing towards the potential of targeting PP2A for therapy in tauopathies, although this relation has yet to be explored in $\mathrm{PD}$. Besides the major role for PP2A, other phosphatases have also been found to act on tau phosphorylation. For instance, PP1 has been reported to act on tau at a limited number of sites in AD brains (T212, T217, S262, S396, S422; Rahman et al., 2005). Similarly, PP2B (aka calcineurin) is able to dephosphorylate tau at S262 and S396 (Rahman et al., 2006) while PP5 is reported to dephosphorylate tau at sites S198S199-S202, T231-S235, S262-S356, S396-S404, and S422 (Gong et al., 2004). An overview of these four classes of phosphatases and the precise sites reported to be regulated by each is given in Table 3.

Thus far, the precise regulatory subunits, which may render specificity of these phosphatases to specific tau phosphosites, have yet to be elucidated and confirmed. Some evidence points to the importance of the $\mathrm{PP} 2 \mathrm{~A}$ regulatory $\mathrm{B} \alpha$ subunit in $\mathrm{PP} 2 \mathrm{~A}$ mediated phosphoregulation of tau. Expression of the $\mathrm{B} \alpha$ subunit of PP2A is decreased in frontal and temporal cortices of AD brain (Sontag et al., 1999, 2004), although it is not known if $\mathrm{B} \alpha$ subunit expression is altered in PD brain. In in vitro assays, the $\mathrm{B} \alpha$ subunit is found to direct the PP2A holoenzyme to microtubules (Xu et al., 2008; Virshup and Shenolikar, 2009), consistent with a role for the $\mathrm{B} \alpha$ subunit in the PP2A holoenzyme dephosphorylating tau.

\section{POTENTIAL INTERPLAY BETWEEN PHOSPHORYLATION OF LRRK2, $\alpha$-SYN, AND TAU}

As LRRK2, $\alpha$-syn, and tau are all three involved in dominant Parkinsonism, the hypothesis has been put forward that these three proteins interact in pathological pathways (Taymans and Cookson, 2010), most notably with synuclein and tau acting as toxic proteins and LRRK2 acting as an upstream modulator.
Experimental evidence from animal models has begun to support the hypothesis of an interaction between these proteins in PD pathology. For instance, toxicity induced by high $\alpha$-syn levels in mouse brain is attenuated in LRRK2 knockout mice, both in transgenic mice with high $\alpha$-syn (inducible CaMKII promoter) expression levels (Lin et al., 2009) as well as after viral delivery of $\alpha$-syn (Daher et al., 2014), although this has not been replicated in other transgenic mice using other promoters to drive LRRK2 and $\alpha$-syn expression such as the Thyl promoter (Herzig et al., 2012) or PrP promoter (Daher et al., 2012) suggesting that the effect is dependent on expression patterns or levels. Several reports show that LRRK2 overexpression affects tau expression or tau phosphorylation (see below), supporting the hypothesis that LRRK2 modulates tau although whether LRRK2 is required for tau toxicity has yet to be tested. Interestingly, the injection of $\alpha$-syn fibrillar strains into mouse brain is shown to induce tau aggregation (Guo et al., 2013), suggesting an interconnection between $\alpha$-syn and tau pathological mechanisms. Studies of relationships between LRRK2, $\alpha$-syn, and tau showing pairwise interactions between these proteins suggest that 3-way interaction studies, which are currently still lacking, are warranted. More information on the overall interplay between these three proteins in $\mathrm{PD}$ pathology can be found in recent reviews covering this topic (Greggio et al., 2011; Tenreiro et al., 2014). With regards to the topic of the present review, we highlight below the relationships between LRRK2, $\alpha$-syn, and tau with regard to their phosphorylation regulation.

As LRRK2 is a kinase, it has been hypothesized that LRRK2 may phosphorylate $\alpha$-syn or tau. Direct phosphorylation of $\alpha$-syn by LRRK2 in vitro has been tested, however, this led to negative results [reference (Khan et al., 2005) and JMT, VB unpublished results]. Also, in LRRK2 overexpressing mice, phosphorylation levels of $\alpha$ syn at S129 were found to be unchanged (Herzig et al., 2012) or even reduced compared to controls (Lin et al., 2009), countering the hypothesis that LRRK2 phosphorylates $\alpha$-syn. Qing and colleagues reported that crude lysates of E. coli expressing LRRK2 as source of enzyme could phosphorylate $\alpha$-syn at S129, suggesting that LRRK2 may regulate $\alpha$-syn phosphorylation in conjunction with bacterial proteins (Qing et al., 2009), although this is unlikely to be representative of a human physiological situation. The direct phosphorylation of $\alpha$-syn by LRRK 2 can therefore be excluded.

There is, however, evidence that LRRK2 may be involved in regulating tau phosphorylation. First, tau pathology has been observed in post-mortem brain of LRRK2 mutation carriers, including in carriers of the I1371V (Biernacka et al., 2011), N1437H (Puschmann etal., 2012), R1441C (Zimprich etal., 2004), Y1699C (Khan etal., 2005), G2019S (Lin etal., 2010), and I2020T (Ujiie et al., 2012) LRRK2 mutations. Interestingly, genetic studies suggest that tau variants influence LRRK2 disease, more specifically by influencing the age of disease onset (Gan-Or et al., 2012), although another study found that interactions between LRRK2 and tau were at the limit of statistical significance (Biernacka et al., 2011). In cells and in vivo, several pieces of evidence point to LRRK2 in regulating tau phosphorylation. MacLeod etal. (2006) found that overexpressed LRRK2 G2019S or I2020T in primary neurons colocalized with phospho-tau punctae in axons. Overexpression of LRRK2 via 
Table 3 | Overview of different classes of phosphatases reported to regulate tau phosphorylation sites, including PP1, PP2A, PP2B, and PP5.

\begin{tabular}{|c|c|c|c|c|}
\hline Site & PP1 & PP2A & PP2B & PP5 \\
\hline S198 & & & & Gong etal. (2004) \\
\hline S199 & Liu etal. (2005) & Liu et al. (2005) & $\begin{array}{l}\text { Saito et al. (1995), Bennecib et al. (2000), } \\
\text { Liu et al. (2005), Rahman et al. (2006) }\end{array}$ & Gong etal. (2004), Liu etal. (2005) \\
\hline S202 & Liu etal. (2005) & $\begin{array}{l}\text { Liu etal. (2005), Kuszczyk etal. } \\
\text { (2009), Martin etal. (2009) }\end{array}$ & $\begin{array}{l}\text { Saito et al. (1995), Bennecib etal. (2000), } \\
\text { Liu et al. (2005), Rahman et al. (2006) }\end{array}$ & Gong etal. (2004), Liu et al. (2005) \\
\hline T205 & Liu etal. (2005) & $\begin{array}{l}\text { Liu etal. (2005), Kuszczyk et al. } \\
\text { (2009), Martin etal. (2009) }\end{array}$ & $\begin{array}{l}\text { Saito et al. (1995), Bennecib et al. (2000), } \\
\text { Liu et al. (2005), Rahman et al. (2006) }\end{array}$ & Liu et al. (2005) \\
\hline T212 & $\begin{array}{l}\text { Liu etal. (2005), } \\
\text { Rahman et al. (2005) }\end{array}$ & Liu et al. (2005) & $\begin{array}{l}\text { Saito et al. (1995), Bennecib etal. (2000), } \\
\text { Liu et al. (2005), Rahman et al. (2006) }\end{array}$ & Liu et al. (2005) \\
\hline S214 & Liu etal. (2005) & Liu et al. (2005) & $\begin{array}{l}\text { Saito et al. (1995), Bennecib et al. (2000), } \\
\text { Liu et al. (2005), Rahman et al. (2006) }\end{array}$ & Liu et al. (2005) \\
\hline $\mathrm{T} 217$ & Rahman et al. (2005) & & $\begin{array}{l}\text { Saito et al. (1995), Bennecib etal. (2000), } \\
\text { Rahman etal. (2006) }\end{array}$ & \\
\hline T231 & & Saito etal. (1995), Chen etal. (2008) & & Gong etal. (2004) \\
\hline S235 & Liu etal. (2005) & $\begin{array}{l}\text { Saito et al. (1995), Liu et al. (2005), } \\
\text { Chen et al. (2008) }\end{array}$ & $\begin{array}{l}\text { Saito et al. (1995), Bennecib et al. (2000), } \\
\text { Liu et al. (2005), Rahman et al. (2006) }\end{array}$ & Gong etal. (2004), Liu et al. (2005) \\
\hline S262 & $\begin{array}{l}\text { Liu etal. (2005), } \\
\text { Rahman et al. (2005) }\end{array}$ & $\begin{array}{l}\text { Saito et al. (1995), Liu etal. (2005), } \\
\text { Chen et al. (2008), Martin etal. (2009) }\end{array}$ & $\begin{array}{l}\text { Saito etal. (1995), Bennecib etal. (2000), } \\
\text { Liu et al. (2005), Rahman et al. (2006) }\end{array}$ & Gong etal. (2004), Liu etal. (2005) \\
\hline $\begin{array}{l}\text { S293 } \\
\text { S324 }\end{array}$ & & & & \\
\hline S356 & & $\begin{array}{l}\text { Saito et al. (1995), Chen et al. (2008), } \\
\text { Martin et al. (2009) }\end{array}$ & & Gong et al. (2004) \\
\hline S396 & $\begin{array}{l}\text { Liu et al. (2005), } \\
\text { Rahman et al. (2005) }\end{array}$ & Liu et al. (2005) & $\begin{array}{l}\text { Saito et al. (1995), Bennecib et al. (2000), } \\
\text { Liu et al. (2005), Rahman et al. (2006) }\end{array}$ & Gong etal. (2004), Liu etal. (2005) \\
\hline S404 & Liu etal. (2005) & $\begin{array}{l}\text { Saito et al. (1995), Liu et al. (2005), } \\
\text { Chen etal. (2008) }\end{array}$ & $\begin{array}{l}\text { Saito et al. (1995), Bennecib et al. (2000), } \\
\text { Liu et al. (2005), Rahman etal. (2006) }\end{array}$ & Gong etal. (2004), Liu etal. (2005) \\
\hline S409 & Liu etal. (2005) & Liu etal. (2005) & $\begin{array}{l}\text { Saito et al. (1995), Bennecib et al. (2000), } \\
\text { Liu et al. (2005), Rahman et al. (2006) }\end{array}$ & Liu et al. (2005) \\
\hline S422 & Rahman et al. (2005) & & $\begin{array}{l}\text { Saito et al. (1995), Bennecib etal. (2000), } \\
\text { Rahman etal. (2006) }\end{array}$ & Gong et al. (2004) \\
\hline
\end{tabular}

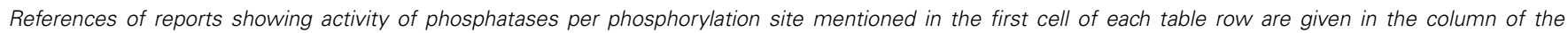
corresponding phosphatase class. See text for a list of reviews discussing non-phosphatase tau phosphorylation regulators.

the ThyI promoter left tau and phospho-tau (S202/T205) levels unchanged in mouse brains (Herzig et al., 2012), although S202 phosphorylation levels were found to be enhanced in brains of BAC transgenic mice expressing LRRK2 G2019S (Melrose et al., 2010). In Drosophila, overexpression of LRRK2 G2019S is reported to affect tau dendritic localization and promote tau phosphorylation at T212 through the recruitment of GSK3 $\beta$ (Lin et al., 2010). Interestingly, LRRK2 has been shown to phosphorylate tubulinassociated tau but not free tau (Kawakami et al., 2012). This last finding may be related to the observations in cells that LRRK2 can in certain conditions translocate to skein-like cytoplasmic pools. Although these skein-like cytoplasmic pools have yet to be fully characterized, at least a portion of these are associated to microtubules (Kett et al., 2012). This points to a mechanism whereby LRRK2 may be recruited to microtubules where it may regulate tau phosphorylation with other kinase or phosphatase partners.

In relation to our knowledge of phosphatases of LRRK2, $\alpha$ syn, and tau and the pathogenic nature of phosphorylations in these proteins, a strategy to target phosphatases in a way that will counteract PD-associated phosphorylation can be proposed. To target LRRK2 disease-related phosphorylations, PP1 would be targeted in order to modulate phosphorylation at its ANKLRR interdomain phosphorylation sites to a 'healthy' level. For instance, pharmacological inhibition of PP1 was shown to increase the S910/S935/S955/S973 phosphorylation to levels comparable to WT. Also, PP1 inhibition was able to reduce the prevalence of LRRK2 presence in skein-like structures observed with several hypophosphorylated disease mutants (Lobbestael et al., 2013). This effect is consistent with a reduction of microtubule associated 
LRRK2 and therefore reduced risk of LRRK2-mediated tau hyperphosphorylation, suggesting that PP1 inhibition may be a viable therapeutic strategy to inhibit LRRK2 mediated pathology. Thus far, the specific composition of the PP1 holoenzyme targeting the ANK-LRR interdomain sites remains to be elucidated prior to developing LRRK2-specific phosphoregulation strategies. Also, the elucidation of phosphatases regulating other sites, such as S1292, may also reveal other potential phosphatase targets for potential therapies targeting LRRK2 phosphorylation.

For $\alpha$-syn, targeting PP2A holo-enzymes is a preferred strategy, more specifically through the activation of PP2A to reduce $\alpha$-synS129 phosphorylation levels. The potential of this approach has been shown by pharmacologically enhancing PP2A activity (see above; Lee et al., 2011). The precise PP2A holoenzyme composition for $\alpha$-syn-S129 has begun to be elucidated, with a preference for the $\mathrm{B}$ regulatory subunit above $\mathrm{B}^{\prime}$ and $\mathrm{B}^{\prime \prime}$ subunits. Further elucidation of the preferred $\mathrm{C}$ (catalytic) and A (scaffolding) subunits for $\alpha$-syn-S129 will allow development of phosphatase activation by targeting the PP2A holoenzyme.

For tau, several phosphatases may be targeted, including PP2A, $\mathrm{PP} 1, \mathrm{PP} 2 \mathrm{~B}$, or PP5. The predominant role of PP2A suggests that activation of PP2A may also be a beneficial therapeutic strategy. One issue is whether separate PP2A holoenzymes are responsible for dephosphorylation of tau at the separate phosphosites. Specifically for PD, it may be expected that dephosphorylation of tau at PD hyperphosphorylation sites should be targeted prioritarily, including T181, S184, S195, S198, S237, S400 (Duka et al., 2013). Further research will be needed to describe the PD-tau phosphorylations and their regulation.

\section{TARGETING OF PHOSPHATASES}

Modulation of phosphorylation levels of disease proteins is an attractive approach to develop disease modifying therapies. For instance, much effort has been spent on targeting kinases responsible for pathogenic phosphorylations. Kinases are also attractive drug targets. Indeed, attrition rates during development of drugs acting on kinases are lower than for most other classes of drugs (Walker and Newell, 2009). An important factor to bear in mind with pharmacological inhibition of kinases is that this will influence the phosphorylation levels of all of the kinase's substrates, both in the disease protein as well as for all of its other substrates. Therefore, for key phosphorylations, it may be necessary to target phosphorylations through other means than by targeting kinases. One possibility is to target phosphatases.

Phosphatases are divided into different classes, including phosphoprotein phosphatases (PPP), metal-dependent protein phosphatases and protein tyrosine phosphatases (PTP). Phosphatases from the PPP class are responsible for the vast majority of dephosphorylations of central nervous system proteins. PPPs, such as PP1 and PP2A class phosphatases, have the characteristic of functioning as a holoenzyme composed of two or more subunits, including a catalytic subunit as well as regulatory subunits. Interestingly, there are few catalytic subunits in the PPP family and the regulatory subunits have therefore generally been thought to confer substrate specificity to the holoenzyme. Emerging structural evidence is supporting this view, namely that phosphatase holoenzymes of the PPP family associate in a structured way and that this structure determines substrate specificity of the dephosphorylation. Some examples are the interaction between PP1 and spinophilin, a complex found in neurons (Ragusa et al., 2010), and the PP1 $\gamma$-MYPT (myosin phosphatase; PPP1R12A) complex that acts as a myosin phosphatase in muscle (Terrak et al., 2014; Yamashiro et al., 2008). Based on this knowledge, it has been proposed that by targeting the holoenzyme structure, for instance by molecules which disrupt substrate-phosphatase holoenzyme complex, one can specifically modulate phosphorylation levels of proteins (McConnell and Wadzinski, 2009; Tsaytler and Bertolotti, 2013; see conceptual schematic in Figure 4). Based on the knowledge of the phosphatases responsible for dephosphorylation of specific phosphosites of proteins, such as emerging knowledge of the composition of phosphatase holoenzymes dephosphorylating specific sites in $\alpha$-syn, LRRK2, and tau, the specific modulation of phosphorylation levels of single phosphosites is theoretically possible. Further work, including further identification and characterization of specific phosphatase holoenzyme compositions for $\alpha$-syn, LRRK2, and tau and development of modulators of phosphatase holoenzyme complexes with their specific substrates, is required to test the efficacy of this approach.

\section{CONCLUSION}

The three main proteins linked to Parkinsonism, $\alpha$-syn, tau, and LRRK2 all display phosphorylations which are modified in disease. The phosphorylation changes are the result of a balance between activity of kinases and phosphatases. Emerging evidence points to phosphatases regulating different pathological phosphorylations in these three proteins, primarily PP1 for LRRK2 and PP2A for $\alpha$-syn and tau. It appears now feasible to target phosphatases of $\alpha$-syn, tau, and LRRK2 in order to alleviate pathology mediated by pathological phosphorylation of these disease proteins. In order for this approach to reach its full potential, additional research will be required further linking individual or clustered phosphorylation events in these three proteins to disease. Also,

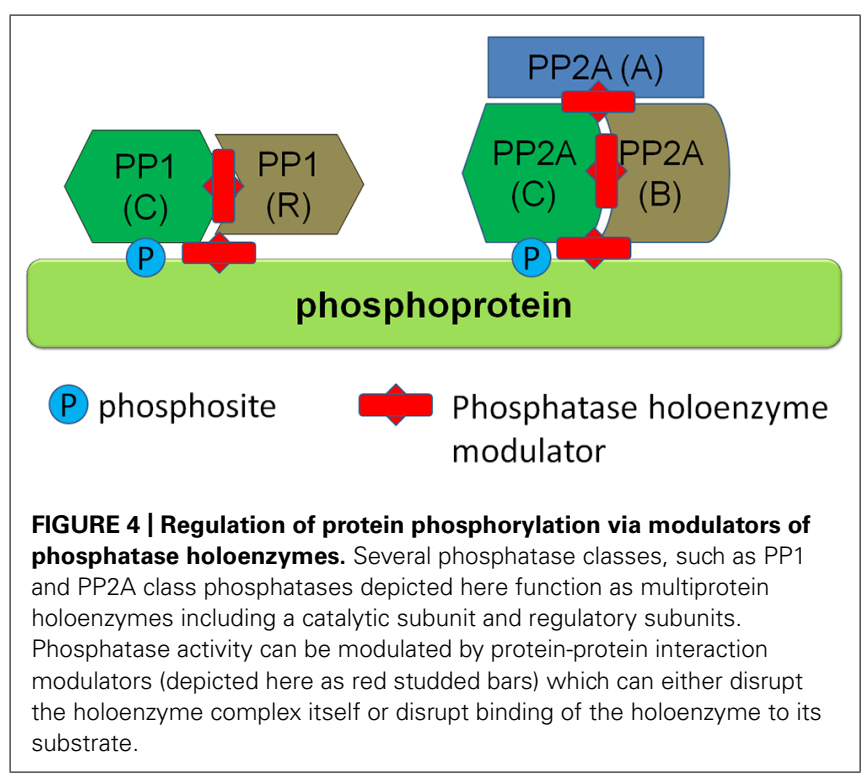


refined knowledge of the precise holoenzyme compositions for each pathological phosphorylation is necessary to develop highly specific phosphatase holoenzyme modulators.

\section{REFERENCES}

Anderson, J. P., Walker, D. E., Goldstein, J. M., De Laat, R., Banducci, K., Caccavello, R. J., et al. (2006). Phosphorylation of Ser-129 is the dominant pathological modification of alpha-synuclein in familial and sporadic Lewy body disease. J. Biol. Chem. 281, 29739-29752. doi: 10.1074/jbc.M600933200

Bennecib, M., Gong, C. X., Grundke-Iqbal, I., and Iqbal, K. (2000). Role of protein phosphatase-2A and -1 in the regulation of GSK-3, cdk5, and cdc2 and the phosphorylation of tau in rat forebrain. FEBS Lett. 485, 87-93. doi: 10.1016/S0014-5793(00)02203-1

Biernacka, J. M., Armasu, S. M., Cunningham, J. M., Ahlskog, J. E., Chung, S. J., and Maraganore, D. M. (2011). Do interactions between SNCA, MAPT, and LRRK2 genes contribute to Parkinson's disease susceptibility? Parkinsonism Relat. Disord. 17, 730-736. doi: 10.1016/j.parkreldis.2011.07.001

Bollen, M., Peti, W., Ragusa, M. J., and Beullens, M. (2010). The extended PP1 toolkit: designed to create specificity. Trends Biochem. Sci. 35, 450-458. doi: 10.1016/j.tibs.2010.03.002

Braithwaite, S. P., Voronkov, M., Stock, J. B., and Mouradian, M. M. (2012). Targeting phosphatases as the next generation of disease modifying therapeutics for Parkinson's disease. Neurochem. Int. 61, 899-906. doi: 10.1016/j.neuint.2012. 01.031

Buee, L., Bussiere, T., Buee-Scherrer, V., Delacourte, A., and Hof, P. R. (2000). Tau protein isoforms, phosphorylation and role in neurodegenerative disorders. Brain Res. Brain Res. Rev. 33, 95-130. doi: 10.1016/S0165-0173(00)00019-9

Chartier-Harlin, M. C., Kachergus, J., Roumier, C., Mouroux, V., Douay, X., Lincoln, S., et al. (2004). Alpha-synuclein locus duplication as a cause of familial Parkinson's disease. Lancet 364, 1167-1169. doi: 10.1016/S0140-6736(04)17103-1

Chen, L., and Feany, M. B. (2005). Alpha-synuclein phosphorylation controls neurotoxicity and inclusion formation in a Drosophila model of Parkinson disease. Nat. Neurosci. 8, 657-663. doi: 10.1038/nn1443

Chen, L., Periquet, M., Wang, X., Negro, A., Mclean, P. J., Hyman, B. T., et al. (2009). Tyrosine and serine phosphorylation of alpha-synuclein have opposing effects on neurotoxicity and soluble oligomer formation. J. Clin. Invest. 119, 3257-3265 doi: 10.1172/JCI39088

Chen, S., Li, B., Grundke-Iqbal, I., and Iqbal, K. (2008). I1PP2A affects tau phosphorylation via association with the catalytic subunit of protein phosphatase $2 \mathrm{~A}$. J. Biol. Chem. 283, 10513-10521. doi: 10.1074/jbc.M709852200M709852200

Choi, H. G., Zhang, J., Deng, X., Hatcher, J. M., Patricelli, M. P., Zhao, Z., et al. (2012). Brain penetrant LRRK2 inhibitor. ACS Med. Chem. Lett. 3, 658-662. doi $10.1021 / \mathrm{ml} 300123 \mathrm{a}$

Daher, J. P., Pletnikova, O., Biskup, S., Musso, A., Gellhaar, S., Galter, D., et al. (2012). Neurodegenerative phenotypes in an A53T alpha-synuclein transgenic mouse model are independent of LRRK2. Hum. Mol. Genet. 21, 2420-2431. doi: $10.1093 / \mathrm{hmg} / \mathrm{dds} 057$

Daher, J. P., Volpicelli-Daley, L. A., Blackburn, J. P., Moehle, M. S., and West, A. B. (2014). Abrogation of alpha-synuclein-mediated dopaminergic neurodegeneration in LRRK2-deficient rats. Proc. Natl. Acad. Sci. U.S.A. 111, 9289-9294. doi: 10.1073/pnas.14032151111403215111

Delbroek, L., Van Kolen, K., Steegmans, L., Da Cunha, R., Mandemakers, W., Daneels, G., et al. (2013). Development of an enzyme-linked immunosorbent assay for detection of cellular and in vivo LRRK2 S935 phosphorylation. J. Pharm. Biomed. Anal. 76, 49-58. doi: 10.1016/j.jpba.2012.12.002

Del Ser, T., Steinwachs, K. C., Gertz, H. J., Andres, M. V., Gomez-Carrillo, B., Medina, M., et al. (2013). Treatment of Alzheimer's disease with the GSK-3 inhibitor tideglusib: a pilot study. J. Alzheimers. Dis. 33, 205-215. doi: 10.3233/JAD-2012120805

Deng, X., Dzamko, N., Prescott, A., Davies, P., Liu, Q., Yang, Q., et al. (2011). Characterization of a selective inhibitor of the Parkinson's disease kinase LRRK2. Nat. Chem. Biol. 7, 203-205. doi: 10.1038/nchembio.538

Doggett, E. A., Zhao, J., Mork, C. N., Hu, D., and Nichols, R. J. (2012). Phosphorylation of LRRK2 serines 955 and 973 is disrupted by Parkinson's disease mutations and LRRK2 pharmacological inhibition. J. Neurochem. 120, 37-45. doi: 10.1111/j.1471-4159.2011.07537.x

Duka, V., Lee, J. H., Credle, J., Wills, J., Oaks, A., Smolinsky, C., et al. (2013). Identification of the sites of tau hyperphosphorylation and activation of tau kinases in synucleinopathies and Alzheimer's diseases. PLoS ONE 8:e75025. doi: 10.1371/journal.pone.0075025

Dzamko, N., Chua, G., Ranola, M., Rowe, D. B., and Halliday, G. M. (2013). Measurement of LRRK2 and Ser910/935 phosphorylated LRRK2 in peripheral blood mononuclear cells from idiopathic Parkinson's disease patients. J. Parkinsons Dis. 3, 145-152. doi: 10.3233/JPD-130174

Dzamko, N., Deak, M., Hentati, F., Reith, A. D., Prescott, A. R., Alessi, D. R., et al. (2010). Inhibition of LRRK2 kinase activity leads to dephosphorylation of Ser(910)/Ser(935), disruption of 14-3-3 binding and altered cytoplasmic localization. Biochem. J. 430, 405-413. doi: 10.1042/BJ20100784

Dzamko, N., Inesta-Vaquera, F., Zhang, J., Xie, C., Cai, H., Arthur, S., et al. (2012). The IkappaB kinase family phosphorylates the Parkinson's disease kinase LRRK2 at Ser935 and Ser910 during Toll-like receptor signaling. PLoS ONE 7:e39132. doi: 10.1371/journal.pone.0039132

Fujiwara, H., Hasegawa, M., Dohmae, N., Kawashima, A., Masliah, E., Goldberg, M. S., et al. (2002). alpha-Synuclein is phosphorylated in synucleinopathy lesions. Nat. Cell Biol. 4, 160-164. doi: 10.1038/ncb748

Gan-Or, Z., Bar-Shira, A., Mirelman, A., Gurevich, T., Giladi, N., and Orr-Urtreger, A. (2012). The age at motor symptoms onset in LRRK2-associated Parkinson's disease is affected by a variation in the MAPT locus: a possible interaction. J. Mol. Neurosci. 46, 541-544. doi: 10.1007/s12031-011-9641-0

Gasser, T. (2009). Molecular pathogenesis of Parkinson disease: insights from genetic studies. Expert Rev. Mol. Med. 11, e22. doi: 10.1017/S1462399409001148

Gloeckner, C. J., Boldt, K., Von Zweydorf, F., Helm, S., Wiesent, L., Sarioglu, H., et al. (2010). Phosphopeptide analysis reveals two discrete clusters of phosphorylation in the N-terminus and the Roc domain of the Parkinson-disease associated protein kinase LRRK2. J. Proteome Res. 9, 1738-1745. doi: 10.1021/ pr9008578

Gong, C. X., Liu, F., Wu, G., Rossie, S., Wegiel, J., Li, L., et al. (2004). Dephosphorylation of microtubule-associated protein tau by protein phosphatase 5 . J. Neurochem. 88, 298-310. doi: 10.1111/j.1471-4159.2004.02147.x

Greggio, E., Bisaglia, M., Civiero, L., and Bubacco, L. (2011). Leucine-rich repeat kinase 2 and alpha-synuclein: intersecting pathways in the pathogenesis of Parkinson's disease? Mol. Neurodegener. 6:6. doi: 10.1186/1750-1326-6-6

Greggio, E., Taymans, J. M., Zhen, E. Y., Ryder, J., Vancraenenbroeck, R., Beilina, A., et al. (2009). The Parkinson's disease kinase LRRK2 autophosphorylates its GTPase domain at multiple sites. Biochem. Biophys. Res. Commun. 389, 449-454. doi: 10.1016/j.bbrc.2009.08.163

Guo, J. L., Covell, D. J., Daniels, J. P., Iba, M., Stieber, A., Zhang, B., et al. (2013). Distinct alpha-synuclein strains differentially promote tau inclusions in neurons. Cell 154, 103-117. doi: 10.1016/j.cell.2013.05.057

Hasegawa, M., Fujiwara, H., Nonaka, T., Wakabayashi, K., Takahashi, H., Lee, V. M.-Y., et al. (2002). Phosphorylated alpha-synuclein is ubiquitinated in alpha-synucleinopathy lesions. J. Biol. Chem. 277, 49071-49076. doi: 10.1074/jbc.M208046200

Healy, D. G., Falchi, M., O'Sullivan, S. S., Bonifati, V., Durr, A., Bressman, S., et al. (2008). Phenotype, genotype, and worldwide genetic penetrance of LRRK2associated Parkinson's disease: a case-control study. Lancet Neurol. 7, 583-590. doi: 10.1016/S1474-4422(08)70117-0

Henderson-Smith, A., Chow, D., Meechoovet, B., Aziz, M., Jacobson, S. A., Shill, H. A., et al. (2013). SMG1 identified as a regulator of Parkinson's diseaseassociated alpha-synuclein through siRNA screening. PLoS ONE 8:e77711. doi: 10.1371/journal.pone.0077711

Herzig, M. C., Bidinosti, M., Schweizer, T., Hafner, T., Stemmelen, C., Weiss, A., et al. (2012). High LRRK2 levels fail to induce or exacerbate neuronal alpha-synucleinopathy in mouse brain. PLoS ONE 7:e36581. doi: 10.1371/journal.pone. 0036581

Houlden, H., and Singleton, A. B. (2012). The genetics and neuropathology of Parkinson's disease. Acta Neuropathol. 124, 325-338. doi: 10.1007/s00401-0121013-5

Kahle, P. J., Neumann, M., Ozmen, L., and Haass, C. (2000). Physiology and pathophysiology of alpha-synuclein. Cell culture and transgenic animal models based on a Parkinson's disease-associated protein. Ann. N. Y. Acad. Sci. 920, 33-41. doi: 10.1111/j.1749-6632.2000.tb06902.x

Kamikawaji, S., Ito, G., and Iwatsubo, T. (2009). Identification of the autophosphorylation sites of LRRK2. Biochemistry 48, 10963-10975. doi: 10.1021/bi9011379

Kawakami, F., Yabata, T., Ohta, E., Maekawa, T., Shimada, N., Suzuki, M., et al. (2012). LRRK2 phosphorylates tubulin-associated tau but not the free 
molecule: LRRK2-mediated regulation of the tau-tubulin association and neurite outgrowth. PLoS ONE 7:e30834. doi: 10.1371/journal.pone.0030834

Kett, L. R., Boassa, D., Ho, C. C., Rideout, H. J., Hu, J., Terada, M., et al. (2012). LRRK2 Parkinson disease mutations enhance its microtubule association. Hum. Mol. Genet. 21, 890-899. doi: 10.1093/hmg/ddr526

Khan, N. L., Jain, S., Lynch, J. M., Pavese, N., Abou-Sleiman, P., Holton, J. L., et al. (2005). Mutations in the gene LRRK2 encoding dardarin (PARK8) cause familia Parkinson's disease: clinical, pathological, olfactory and functional imaging and genetic data. Brain 128, 2786-2796. doi: 10.1093/brain/awh667

Kramer, T., Schmidt, B., and Lo Monte, F. (2012). Small-molecule inhibitors of GSK-3: structural insights and their application to Alzheimer's disease models. Int. J. Alzheimers Dis. 2012, 381029. doi: 10.1155/2012/381029

Kuszczyk, M., Gordon-Krajcer, W., and Lazarewicz, J. W. (2009). Homocysteineinduced acute excitotoxicity in cerebellar granule cells in vitro is accompanied by PP2A-mediated dephosphorylation of tau. Neurochem. Int. 55, 174-180. doi: 10.1016/j.neuint.2009.02.010

Lambert, J. C., Ibrahim-Verbaas, C. A., Harold, D., Naj, A. C., Sims, R., Bellenguez, C., et al. (2013). Meta-analysis of 74,046 individuals identifies 11 new susceptibility loci for Alzheimer's disease. Nat. Genet. 45, 1452-1458. doi 10.1038/ng.2802ng.2802

Lee, K. W., Chen, W., Junn, E., Im, J. Y., Grosso, H., Sonsalla, P. K., et al. (2011). Enhanced phosphatase activity attenuates \{alpha\}-synucleinopathy in a mouse model. J. Neurosci. 31, 6963-6971. doi: 10.1523/JNEUROSCI.6513-10.2011

Li, X., Wang, Q. J., Pan, N., Lee, S., Zhao, Y., Chait, B. T., et al. (2011). Phosphorylation-dependent 14-3-3 binding to LRRK2 is impaired by common mutations of familial Parkinson's disease. PLoS ONE 6:e17153. doi 10.1371/journal.pone.0017153

Lin, C. H., Tsai, P. I., Wu, R. M., and Chien, C. T. (2010). LRRK2 G2019S mutation induces dendrite degeneration through mislocalization and phosphorylation of tau by recruiting autoactivated GSK3ss. J. Neurosci. 30, 13138-13149. doi: 10.1523/JNEUROSCI.1737-10.2010

Lin, X., Parisiadou, L., Gu, X. L., Wang, L., Shim, H., Sun, L., et al. (2009). Leucinerich repeat kinase 2 regulates the progression of neuropathology induced by Parkinson's-disease-related mutant alpha-synuclein. Neuron 64, 807-827. doi: 10.1016/j.neuron.2009.11.006

Liu, F., Grundke-Iqbal, I., Iqbal, K., and Gong, C. X. (2005). Contributions of protein phosphatases PP1, PP2A, PP2B and PP5 to the regulation of tau phosphorylation. Eur. J. Neurosci. 22, 1942-1950. doi: 10.1111/j.1460-9568.2005.04391.x

Lobbestael, E., Baekelandt, V., and Taymans, J. M. (2012). Phosphorylation of LRRK2: from kinase to substrate. Biochem. Soc. Trans. 40, 1102-1110. doi: 10.1042/BST20120128

Lobbestael, E., Zhao, J., Rudenko, I. N., Beylina, A., Gao, F., Wetter, J., et al. (2013). Identification of protein phosphatase 1 as a regulator of the LRRK2 phosphorylation cycle. Biochem. J. 456, 119-128. doi: 10.1042/BJ20121772BJ2 0121772

Lou, H., Montoya, S. E., Alerte, T. N., Wang, J., Wu, J., Peng, X., et al. (2010). Serine 129 phosphorylation reduces the ability of alpha-synuclein to regulate tyrosine hydroxylase and protein phosphatase 2A in vitro and in vivo. J. Biol. Chem. 285, 17648-17661. doi: 10.1074/jbc.M110.100867M110.100867

MacLeod, D., Dowman, J., Hammond, R., Leete, T., Inoue, K., and Abeliovich, A. (2006). The familial Parkinsonism gene LRRK2 regulates neurite process morphology. Neuron 52, 587-593. doi: 10.1016/j.neuron.2006.10.008

Manning, G., Whyte, D. B., Martinez, R., Hunter, T., and Sudarsanam, S. (2002). The protein kinase complement of the human genome. Science 298, 1912-1934. doi: 10.1126/science.1075762298/5600/1912

Martin, L., Latypova, X., and Terro, F. (2011). Post-translational modifications of tau protein: implications for Alzheimer's disease. Neurochem. Int. 58, 458-471. doi: 10.1016/j.neuint.2010.12.023

Martin, L., Latypova, X., Wilson, C. M., Magnaudeix, A., Perrin, M. L., and Terro, F. (2013a). Tau protein phosphatases in Alzheimer's disease: the leading role of PP2A. Ageing Res. Rev. 12, 39-49. doi: 10.1016/j.arr.2012.06.008

Martin, L., Latypova, X., Wilson, C. M., Magnaudeix, A., Perrin, M. L., Yardin, C., et al. (2013b). Tau protein kinases: involvement in Alzheimer's disease. Ageing Res. Rev. 12, 289-309. doi: 10.1016/j.arr.2012.06.003

Martin, L., Magnaudeix, A., Esclaire, F., Yardin, C., and Terro, F. (2009). Inhibition of glycogen synthase kinase-3beta downregulates total tau proteins in cultured neurons and its reversal by the blockade of protein phosphatase-2A. Brain Res. 1252, 66-75. doi: 10.1016/j.brainres.2008.11.057
Mbefo, M. K., Paleologou, K. E., Boucharaba, A., Oueslati, A., Schell, H., Fournier, M., et al. (2010). Phosphorylation of synucleins by members of the Polo-like kinase family. J. Biol. Chem. 285, 2807-2822. doi: 10.1074/jbc.M109.081950

McConnell, J. L., and Wadzinski, B. E. (2009). Targeting protein serine/threonine phosphatases for drug development. Mol. Pharmacol. 75, 1249-1261. doi: 10.1124/mol.108.053140

Melrose, H. L., Dachsel, J. C., Behrouz, B., Lincoln, S. J., Yue, M., Hinkle, K. M., et al. (2010). Impaired dopaminergic neurotransmission and microtubule-associated protein tau alterations in human LRRK2 transgenic mice. Neurobiol. Dis. 40, 503-517. doi: 10.1016/j.nbd.2010.07.010

Moorhead, G. B., Trinkle-Mulcahy, L., and Ulke-Lemee, A. (2007). Emerging roles of nuclear protein phosphatases. Nat. Rev. Mol. Cell Biol. 8, 234-244. doi: $10.1038 / \mathrm{nrm} 2126$

Muda, K., Bertinetti, D., Gesellchen, F., Hermann, J. S., Von Zweydorf, F., Geerlof, A., et al. (2014). Parkinson-related LRRK2 mutation R1441C/G/H impairs PKA phosphorylation of LRRK2 and disrupts its interaction with 14-3-3. Proc. Natl. Acad. Sci. U.S.A. 111, E34-E43. doi: 10.1073/pnas.131270111113127 01111

Nalls, M. A., Plagnol, V., Hernandez, D. G., Sharma, M., Sheerin, U. M., Saad, M., et al. (2011). Imputation of sequence variants for identification of genetic risks for Parkinson's disease: a meta-analysis of genome-wide association studies. Lancet 377, 641-649. doi: 10.1016/S0140-6736(10)62345-8

Neumann, M., Kahle, P. J., Giasson, B. I., Ozmen, L., Borroni, E., Spooren, W., et al. (2002). Misfolded proteinase K-resistant hyperphosphorylated alphasynuclein in aged transgenic mice with locomotor deterioration and in human alpha-synucleinopathies. J. Clin. Invest. 110, 1429-1439. doi: 10.1172/JCI200 215777

Nichols, R. J., Dzamko, N., Morrice, N. A., Campbell, D. G., Deak, M., Ordureau, A., et al. (2010). 14-3-3 binding to LRRK2 is disrupted by multiple Parkinson's disease-associated mutations and regulates cytoplasmic localization. Biochem. J. 430, 393-404. doi: 10.1042/BJ20100483

Oueslati, A., Schneider, B. L., Aebischer, P., and Lashuel, H. A. (2013). Polo-like kinase 2 regulates selective autophagic alpha-synuclein clearance and suppresses its toxicity in vivo. Proc. Natl. Acad. Sci. U.S.A. 110, E3945-E3954. doi: 10.1073/pnas.13099911101309991110

Paleologou, K. E., Oueslati, A., Shakked, G., Rospigliosi, C. C., Kim, H. Y., Lamberto, G. R., et al. (2010). Phosphorylation at S87 is enhanced in synucleinopathies, inhibits alpha-synuclein oligomerization, and influences synuclein-membrane interactions. J. Neurosci. 30, 3184-3198. doi: 10.1523/JNEUROSCI.592209.2010

Peng, X., Tehranian, R., Dietrich, P., Stefanis, L., and Perez, R. G. (2005). Alpha-synuclein activation of protein phosphatase $2 \mathrm{~A}$ reduces tyrosine hydroxylase phosphorylation in dopaminergic cells. J. Cell Sci. 118, 3523-3530. doi: 10.1242/jcs.02481

Perez-Revuelta, B. I., Hettich, M. M., Ciociaro, A., Rotermund, C., Kahle, P. J., Krauss, S., et al. (2014). Metformin lowers Ser-129 phosphorylated alphasynuclein levels via mTOR-dependent protein phosphatase $2 \mathrm{~A}$ activation. Cell Death Dis. 5, e1209. doi: 10.1038/cddis.2014.175cddis2014175

Polymeropoulos, M. H., Lavedan, C., Leroy, E., Ide, S. E., Dehejia, A., Dutra, A., et al. (1997). Mutation in the alpha-synuclein gene identified in families with Parkinson's disease. Science 276, 2045-2047. doi: 10.1126/science.276.5321.2045

Pungaliya, P. P., Bai, Y., Lipinski, K., Anand, V. S., Sen, S., Brown, E. L., et al. (2010). Identification and characterization of a leucine-rich repeat kinase 2 (LRRK2) consensus phosphorylation motif. PLoS ONE 5:e13672. doi: 10.1371/journal.pone.0013672

Puschmann, A., Englund, E., Ross, O. A., Vilarino-Guell, C., Lincoln, S. J., Kachergus, J. M., et al. (2012). First neuropathological description of a patient with Parkinson's disease and LRRK2 p.N1437H mutation. Parkinsonism Relat. Disord. 18, 332-338. doi: 10.1016/j.parkreldis.2011.11.019

Qing, H., Wong, W., McGeer, E. G., and McGeer, P. L. (2009). Lrrk2 phosphorylates alpha synuclein at serine 129: Parkinson disease implications. Biochem. Biophys. Res. Commun. 387, 149-152. doi: 10.1016/j.bbrc.2009.06.142

Ragusa, M. J., Dancheck, B., Critton, D. A., Nairn, A. C., Page, R., and Peti, W. (2010). Spinophilin directs protein phosphatase 1 specificity by blocking substrate binding sites. Nat. Struct. Mol. Biol. 17, 459-464. doi: 10.1038/nsmb.1786

Rahman, A., Grundke-Iqbal, I., and Iqbal, K. (2005). Phosphothreonine-212 of Alzheimer abnormally hyperphosphorylated tau is a preferred substrate of protein phosphatase-1. Neurochem. Res. 30, 277-287. doi: 10.1007/s11064-005-2483-9 
Rahman, A., Grundke-Iqbal, I., and Iqbal, K. (2006). PP2B isolated from human brain preferentially dephosphorylates Ser-262 and Ser-396 of the Alzheimer disease abnormally hyperphosphorylated tau. J. Neural. Transm. 113, 219-230. doi: 10.1007/s00702-005-0313-5

Reyniers, L., Del Giudice, M.-G., Civiero, L., Belluzzi, E., Lobbestael, E., Beilina, A., et al. (2014). Differential protein-protein interactions of LRRK1 and LRRK2 indicate roles in distinct cellular signaling pathways. J. Neurochem. 131, 239-250. doi: $10.1111 /$ jnc. 12798

Reynolds, A., Doggett, E. A., Riddle, S. M., Lebakken, C. S., and Nichols, R. J. (2014). LRRK2 kinase activity and biology are not uniformly predicted by its autophosphorylation and cellular phosphorylation site atatus. Front. Mol. Neurosci. 7:54. doi: 10.3389/fnmol.2014.00054

Saito, T., Ishiguro, K., Uchida, T., Miyamoto, E., Kishimoto, T., and Hisanaga, S. (1995). In situ dephosphorylation of tau by protein phosphatase $2 \mathrm{~A}$ and $2 \mathrm{~B}$ in fetal rat primary cultured neurons. FEBS Lett. 376, 238-242. doi: 10.1016/00145793(95)01292-0

Satake, W., Nakabayashi, Y., Mizuta, I., Hirota, Y., Ito, C., Kubo, M., et al. (2009). Genome-wide association study identifies common variants at four loci as genetic risk factors for Parkinson's disease. Nat. Genet. 41, 1303-1307. doi: $10.1038 / \mathrm{ng} .485$

Sharma, M., Ioannidis, J. P., Aasly, J. O., Annesi, G., Brice, A., Van Broeckhoven, C., et al. (2012). Large-scale replication and heterogeneity in Parkinson disease genetic loci. Neurology 79, 659-667. doi: 10.1212/WNL.0b013e318264e353

Sheng, Z., Zhang, S., Bustos, D., Kleinheinz, T., Le Pichon, C. E., Dominguez, S. L., et al. (2012). Ser1292 autophosphorylation is an indicator of LRRK2 kinase activity and contributes to the cellular effects of PD mutations. Sci. Transl. Med 4, 164ral61. doi: 10.1126/scitranslmed.30044854/164/164ral61

Simon-Sanchez, J., Schulte, C., Bras, J. M., Sharma, M., Gibbs, J. R., Berg, D., et al. (2009). Genome-wide association study reveals genetic risk underlying Parkinson's disease. Nat. Genet. 41, 1308-1312. doi: 10.1038/ng.487

Singleton, A. B., Farrer, M., Johnson, J., Singleton, A., Hague, S., Kachergus, J., et al. (2003). alpha-Synuclein locus triplication causes Parkinson's disease. Science 302, 841. doi: 10.1126/science.1090278302/5646/841

Sontag, E., Luangpirom, A., Hladik, C., Mudrak, I., Ogris, E., Speciale, S., et al. (2004). Altered expression levels of the protein phosphatase 2A ABalphaC enzyme are associated with Alzheimer disease pathology. J. Neuropathol. Exp. Neurol. 63, 287-301.

Sontag, E., Nunbhakdi-Craig, V., Lee, G., Brandt, R., Kamibayashi, C., Kuret, J., et al. (1999). Molecular interactions among protein phosphatase 2A, tau, and microtubules. Implications for the regulation of tau phosphorylation and the development of tauopathies. J. Biol. Chem. 274, 25490-25498. doi: 10.1074/jbc.274.36.25490

Spillantini, M. G., Schmidt, M. L., Lee, V. M., Trojanowski, J. Q., Jakes, R., and Goedert, M. (1997). Alpha-synuclein in Lewy bodies. Nature 388, 839-840. doi: $10.1038 / 42166$

Takahashi, M., Kanuka, H., Fujiwara, H., Koyama, A., Hasegawa, M., Miura, M., et al. (2003). Phosphorylation of alpha-synuclein characteristic of synucleinopathy lesions is recapitulated in alpha-synuclein transgenic Drosophila. Neurosci. Lett. 336, 155-158. doi: 10.1016/S0304-3940(02)01258-2

Taymans, J. M., and Cookson, M. (2010). Mechanisms of dominant parkinsonism; the toxic triangle of LRRK2, alpha-synuclein and tau. Bioessays 32, 227-235. doi: 10.1002/bies.200900163

Tell, V., and Hilgeroth, A. (2013). Recent developments of protein kinase inhibitors as potential AD therapeutics. Front. Cell. Neurosci. 7, 189. doi: 10.3389/fncel.2013.00189

Tenreiro, S., Eckermann, K., and Outeiro, T. F. (2014). Protein phosphorylation in neurodegeneration: friend or foe? Front. Mol. Neurosci. 7, 42. doi $10.3389 /$ fnmol.2014.00042

Terrak, M., Kerff, F., Langsetmo, K., Tao, T., and Dominguez, R. (2004). Structural basis of protein phosphatase 1 regulation. Nature 429, 780-784. doi: 10.1038 /nature02582

Tsaytler, P., and Bertolotti, A. (2013). Exploiting the selectivity of protein phosphatase 1 for pharmacological intervention. FEBS J. 280, 766-770. doi: 10.1111/j.1742-4658.2012.08535.x
Ujiie, S., Hatano, T., Kubo, S., Imai, S., Sato, S., Uchihara, T., et al. (2012). LRRK2 I2020T mutation is associated with tau pathology. Parkinsonism Relat. Disord. 18, 819-823. doi: 10.1016/j.parkreldis.2012.03.024

Vancraenenbroeck, R., Lobbestael, E., De Maeyer, M., Baekelandt, V., and Taymans, J. M. (2011). Kinases as targets for Parkinson's disease; from genetics to therapy. CNS Neurol. Disord. Drug Targets 10, 724-740. doi: $10.2174 / 187152711797247858$

Vancraenenbroeck, R., Lobbestael, E., Weeks, S. D., Strelkov, S. V., Baekelandt, V., Taymans, J. M., et al. (2012). Expression, purification and preliminary biochemical and structural characterization of the leucine rich repeat namesake domain of leucine rich repeat kinase 2. Biochim. Biophys. Acta 1824, 450-460. doi: 10.1016/j.bbapap.2011.12.009

Virshup, D. M., and Shenolikar, S. (2009). From promiscuity to precision: protein phosphatases get a makeover. Mol. Cell. 33, 537-545. doi: 10.1016/j.molcel.2009.02.015

Voronkov, M., Braithwaite, S. P., and Stock, J. B. (2011). Phosphoprotein phosphatase 2A: a novel druggable target for Alzheimer's disease. Future Med. Chem. 3, 821-833. doi: 10.4155/fmc.11.47

Walker, I., and Newell, H. (2009). Do molecularly targeted agents in oncology have reduced attrition rates? Nat. Rev. Drug Discov. 8, 15-16. doi: 10.1038/nrd2758

Waxman, E. A., and Giasson, B. I. (2008). Specificity and regulation of casein kinasemediated phosphorylation of alpha-synuclein. J. Neuropathol. Exp. Neurol. 67, 402-416. doi: 10.1097/NEN.0b013e31816fc995

Waxman, E. A., and Giasson, B. I. (2011). Characterization of kinases involved in the phosphorylation of aggregated alpha-synuclein. J. Neurosci. Res. 89, 231-247. doi: 10.1002/jnr.22537

Webber, P. J., Smith, A. D., Sen, S., Renfrow, M. B., Mobley, J. A., and West, A. B. (2011). Autophosphorylation in the leucine-rich repeat kinase 2 (LRRK2) GTPase domain modifies kinase and GTP-binding activities. J. Mol. Biol. 412, 94-110. doi: 10.1016/j.jmb.2011.07.033

West, A. B., Moore, D. J., Choi, C., Andrabi, S. A., Li, X., Dikeman, D., et al. (2007) Parkinson's disease-associated mutations in LRRK2 link enhanced GTP-binding and kinase activities to neuronal toxicity. Hum. Mol. Genet. 16, 223-232. doi: 10.1093/hmg/ddl471

Xu, Y., Chen, Y., Zhang, P., Jeffrey, P. D., and Shi, Y. (2008). Structure of a protein phosphatase 2A holoenzyme: insights into B55-mediated Tau dephosphorylation. Mol. Cell. 31, 873-885. doi: 10.1016/j.molcel.2008.08.006

Yamashiro, S., Yamakita, Y., Totsukawa, G., Goto, H., Kaibuchi, K., Ito, M., et al. (2008). Myosin phosphatase-targeting subunit 1 regulates mitosis by antagonizing polo-like kinase 1. Dev. Cell 14, 787-797. doi: 10.1016/j.devcel.2008.02.013

Zhang, J., Deng, X., Choi, H. G., Alessi, D. R., and Gray, N. S. (2012). Characterization of TAE684 as a potent LRRK2 kinase inhibitor. Bioorg. Med. Chem. Lett. 22, 1864-1869. doi: 10.1016/j.bmcl.2012.01.084

Zimprich, A., Biskup, S., Leitner, P., Lichtner, P., Farrer, M., Lincoln, S., et al. (2004). Mutations in LRRK2 cause autosomal-dominant parkinsonism with pleomorphic pathology. Neuron 44, 601-607. doi: 10.1016/j.neuron.2004.11.005

Conflict of Interest Statement: The authors declare that the research was conducted in the absence of any commercial or financial relationships that could be construed as a potential conflict of interest.

Received: 21 June 2014; accepted: 17 October 2014; published online: 07 November 2014.

Citation: Taymans J-M and Baekelandt V (2014) Phosphatases of $\alpha$-synuclein, LRRK2, and tau: important players in the phosphorylation-dependent pathology of Parkinsonism. Front. Genet. 5:382. doi: 10.3389/fgene.2014.00382

This article was submitted to Systems Biology, a section of the journal Frontiers in Genetics.

Copyright (C) 2014 Taymans and Baekelandt. This is an open-access article distributed under the terms of the Creative Commons Attribution License (CC BY). The use, distribution or reproduction in other forums is permitted, provided the original author(s) or licensor are credited and that the original publication in this journal is cited, in accordance with accepted academic practice. No use, distribution or reproduction is permitted which does not comply with these terms. 